\title{
APLIKASI PENGENALAN KOMPONEN ELEKTRONIKA BERBASIS ANDROID: STUDI KASUS PADA MATA KULIAH ELEKTRONIKA ANALOG DAN DIGITAL
}

\author{
Akbar Jafar ${ }^{1}$, Edi Suhardi Rahman ${ }^{2}$, Syarifuddin Kasim ${ }^{3}$ \\ ${ }^{1}$ Pendidikan Teknik Elektro, Universitas Negeri Makassar \\ akbarjafar9@gmail.com \\ ${ }^{2}$ Pendidikan Teknik Elektro, Universitas Negeri Makassar \\ edisuhardi@unm.ac.id \\ ${ }^{3}$ Pendidikan Teknik Elektro, Universitas Negeri Makassar \\ Syarifuddin.kasim@unm.ac.id
}

\begin{abstract}
ABSTRAK
Mata kuliah elektronika analog dan digital merupakan satu bagian pada urikulum yang ada di perguruan tinggi yang mempelajari tentang komponen-komponen elektronika, integrasi sikuit, rangkaian elektronika dan mendesain rangkaian dan perlatan elektronik baik untuk kebutuhan industry maupun biomedik. Penelitian dilakukan dengan tujuan untuk menghasilkan aplikasi pengenalan komponen-komponen elektronika berbasis android. Data dikumpulkan dengan menggunakan teknik dokumentasi dan angket. Data yang diperoleh pada penelitian ini diolah dengan menggunakan teknik analisis data deskriptif. Pengujian aplikasi yang dibuat dilakukan dengan menggunakan standar ISO 25010 dengan mengambil tiga kriteria, yaitu (1) functionality, (2) performance efficiency, dan (3) usability. Pengujian functionality dilakukan menggunakan metode test case, pengujian performance efficiency dilakukan dengan melakukan instalasi aplikasi pada beberapa jenis smartphone dengan spesifikasi dan versi sistem operasi yang ada pada android. Pengujian usability dilakukan dengan menggunakan kuesioner atau angket. Nilai dari pengujian functionality dinyatakan sangat baik dan dan dapat dikatakan receptable atau dapat diterima. Pengujian performance efficiency telah terpenuhi dan dinyatakan baik sedangkan pengujian usability menunjukkan bahwa aplikasi ini dapat digunakan dengan baik oleh pengguna dengan tingkat persentase $92 \%$.
\end{abstract}

Kata Kunci: Android, Komponen Elektronika, ISO 25010

\section{ANDROID-BASED ELECTRONICS COMPONENT RECOGNITION APPLICATION: A CASE STUDY IN ANALOG AND DIGITAL ELECTRONICS COURSES}

\begin{abstract}
Analog and digital electronics courses are a part of the curriculum at universities that study electronic components, circuit integration, electronic circuits and design electronic circuits and equipment for both industrial and biomedical needs. The research was conducted with the aim of producing an application for the introduction of android-based electronic components. Data were collected using documentation and questionnaire techniques. The data obtained in this study were processed using descriptive data analysis techniques. Testing the application made using the ISO 25010 standard by taking three criteria, namely (1) functionality, (2) performance efficiency, and (3) usability. Functionality testing is carried out using the test case method, performance efficiency testing is carried out by installing applications on several types of smartphones with specifications and versions of the operating system on Android. Usability testing is done by using a questionnaire or questionnaire. The value of the functionality test is stated to be very good and can be said to be acceptable. Performance efficiency testing has been met and declared good while usability testing shows that this application can be used properly by users with a percentage rate of $92 \%$.
\end{abstract}

Keyword: Android, Electronic Components, ISO 25010 


\section{PENDAHULUAN}

Perkembangan teknologi di bidang Elektro (Elektronika) juga berkembang pesat, sehingga dituntut agar dapat mengenali dan memahami komponen yang berkaitan dengan elektronika tersebut, terkuhusus pada kalangan pelajar baik itu siswa ataupun mahasiswa, dan tidak menutup kemungkinan pada kalangan pengajar baik itu guru maupun dosen, bahkan profesi-profesi lain yang berhubungan dengan ilmu Eletronika [1].

Perguruan tinggi yang merupakan lembaga Pendidikan formal harus dapat untuk mengikuti segala bentuk perkembangan teknologi sehingga lulusan yang dihasilkan dapat kompoten baik secara kognitif, afektif dan psikomotorik. Teknologi baru perlu dikenalkan dalam proses perkuliahan agar peserta didik siap dalam menghadapi tantangan pada era kamajuan teknologi. Untuk itu diperlukan ketersedian media pembelajaran dalam rangka peningkatan proses pembelajaran [2].

Meta kuliah elektronika merupakan salah satu kurikulum pembalajaran yang ada pada perguruan tinggi [3]. mata kuliah elektronika berisi mengenai komponen, komponen elektronika, rangkaian elektronika, sirkuit terintegrasi, aplikasi dan desain peralatan elektronik pada industri dan pada bidang biomedik.

Berdasarkan hasil observasi mengenai metode yang digunakan pada pembelajaran yang telah dilaksanakan pada mata kuliah tersebut, diketahui bahwa metode dalam pembelajaran yaitu ceramah dan diskusi dimana materi bersifat kognitif tinggi dan psikomotorik sehingga membutuhkan ruang dan waktu yang lebih. Hal tersebut menyebabkan mahasiswa sulit mengetahui komponenkomponen elektronika dengan cepat dan tepat karena komponennya memiliki beragam jenis yang tidak hanya berpacu kepada satu jenis atau bentuk dalam satu komponen.

Berdasar pada hasil obervasi tersebut, maka penulis menilai bahwa perlunya pemanfaatan teknologi yang dapat mengenalkan komponen elektronika dengan teknologi perangkat android. Dengan adanya aplikasi yang dapat memperkenalkan komponen-komponen elektronika maka mahasiswa yang ingin mempelajari dan memahami komponenkomponen elektronika dapat dengan mudah memperolehnya.

\section{METODE PENELITIAN}

\section{A. Metode Penelitian}

Pada penelitian ini digunakan jenis panelitian pengembangan (Research and Development). Menurut [4] Penelitian (R \& D) merupakan metode penelitian dan pengembangan yang dapat digunakan untuk menghasilkan dan mengembangkan produk tertentu dan dapat juga digunakan untuk menguji keefektifan produk yang dibuat. Model yang digunakan pada pengembangan aplikasi ini yaitu prototyping yang merupakan proses iterative dimana kebutuhan dapat diubah dan diperbaiki antara pengguna dan analis [5].

\section{B. Teknik Pengumpulan Data}

Teknik pengumpulan data yang pakai dalam membangun aplikasi ini yaitu observasi, kuisioner (angket) dan studi pustaka. Observasi dilakukan dalam rangka peninjauan langsung terhadap masalah yang ada [6], kuisioner (angket) diperlukan untuk menghimpun data yang akan digunakan dalam menganalisis kebutuhan pengguna [7], sedangkan studi pustaka dilakukan untuk mengumpulkan data baik dari buku maupun literatur yang berisi landasan teoritis yang digunakan dalam perancangan [8].

\section{HASIL DAN PEMBAHASAN}

\section{A. Desain dan Perancangan Aplikasi}

Aplikasi ini di desain dengan menggunakan pendekatan model prototype. Tahap awal dalam perancangan aplikasi ini yaitu analisis kebutuhan yang dimaksudkan untuk memperoleh informasi mengenai kebutuhan user dalam membangun aplikasi.

Tahap selanjutnya yaitu dengan melakukan perancangan dan desain aplikasi. Pada tahapan ini dilakukan analisis data, pembuatan flowchart, diagram konteks, desain database dan rancangan desain awal aplikasi.

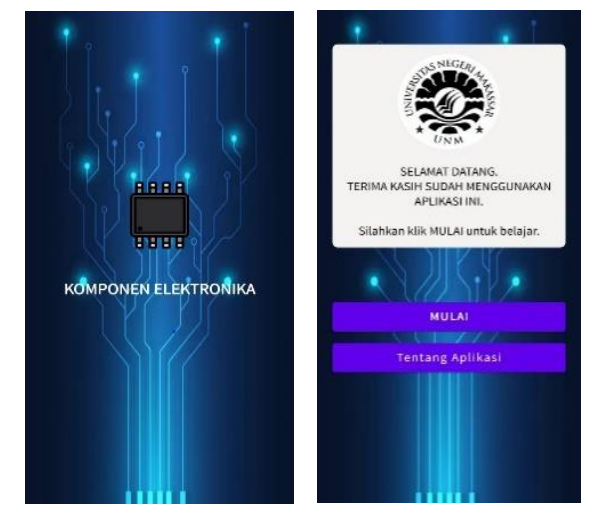

Gambar 1. Halaman Intro dan Menu Utama 


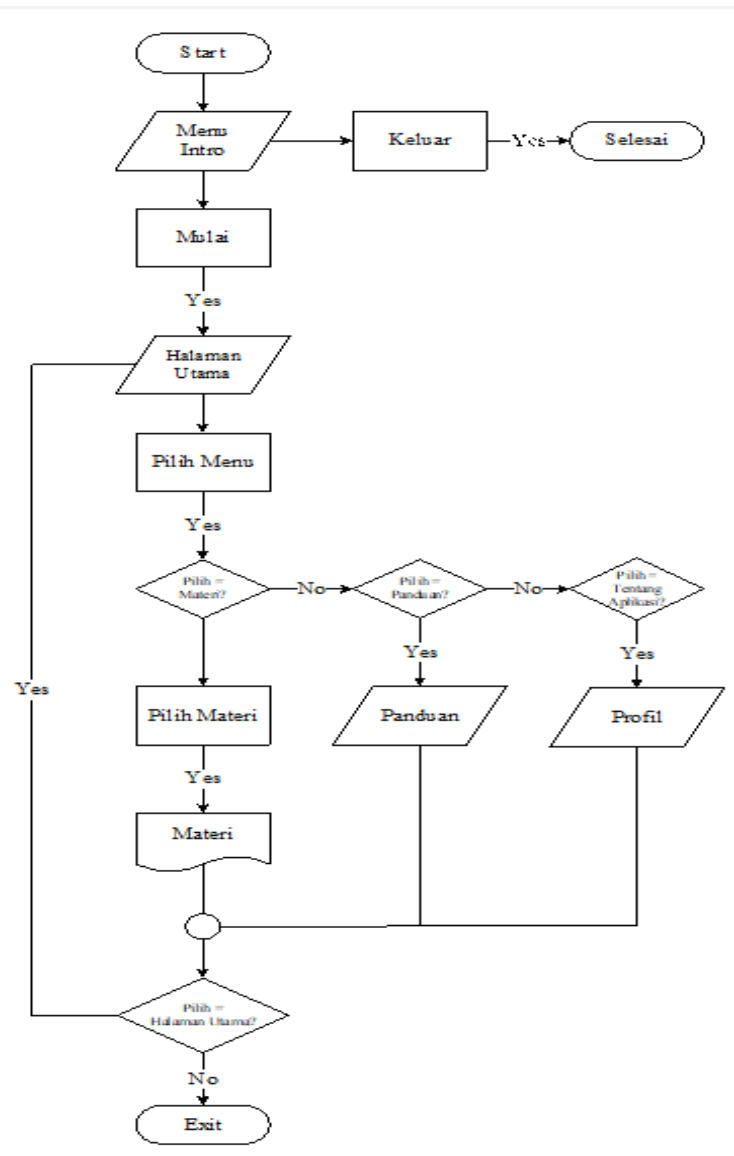

Gambar 2. Flowchart Halaman Utama

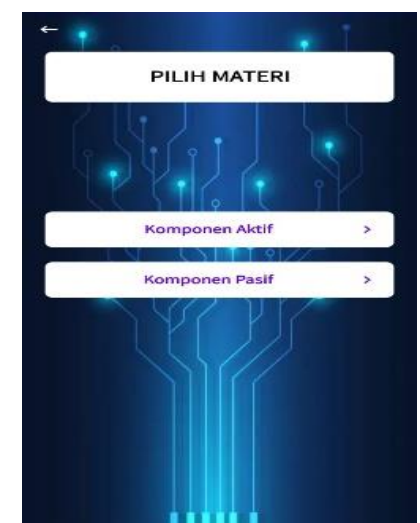

Gambar 3. Halaman Menu Materi

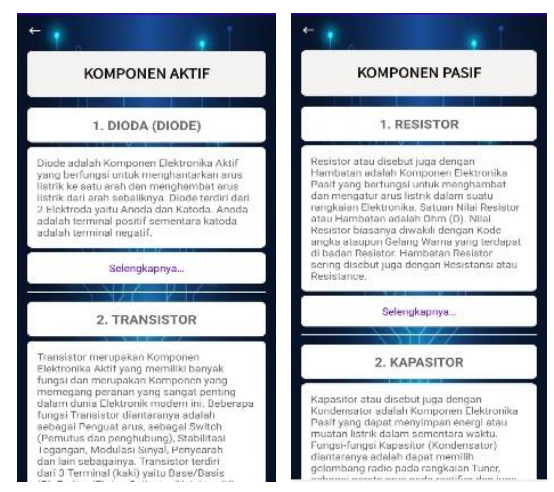

Gambar 4. Halaman Sub Materi Aktif dan Sub Materi Pasif

\section{B. Pengujian Aplikasi}

Pengujian aplikasi dilakukan dengan menggunakan standar ISO 25010 yang dalam pengujiannya dipilih tuga 4 aspek yaitu functional suitability untuk melihat sejauh mana fungsi-fungsi pada aplikasi berjalan sesuai dengan algortima, performance efficiency untuk melihat sejauh mana aplikasi dapat berjalan pada perangkat dan system operasi lain, dan usability dilakukan untuk melihat sejauh mana aplikasi yang dibuat bermanfaat dan mudah digunakan.

\section{Pengujian Funcionality Suitability}

Pengujian functional Suitability dilakukan dengan menguji fungsi-fungsi yang ada pada aplikasi dengan bantuan ahli (Expert judgement) berupa test case. Hasil pengujian dapat di lihat pada Table 1.

TABEL 1. PENILAIAN FUNCTIONAL SUITABILITY

\begin{tabular}{|c|c|c|c|c|}
\hline Validator & $\begin{array}{l}\text { Skor } \\
\text { Perolehan }\end{array}$ & $\begin{array}{l}\text { Skor } \\
\text { Maksimal }\end{array}$ & $\begin{array}{l}\text { Persentase } \\
\text { Kelayakan }\end{array}$ & Kategori \\
\hline $\begin{array}{c}\text { Validator } \\
1\end{array}$ & 13 & 13 & $100 \%$ & $\begin{array}{l}\text { Sangat } \\
\text { Baik }\end{array}$ \\
\hline $\begin{array}{c}\text { Validator } \\
2 \\
\end{array}$ & 13 & 13 & $100 \%$ & $\begin{array}{l}\text { Sangat } \\
\text { Baik }\end{array}$ \\
\hline \multicolumn{4}{|c|}{ Rata-rata } & $\begin{array}{l}\text { Sangat } \\
\text { Baik }\end{array}$ \\
\hline
\end{tabular}

Hasil pengujian ditentukan dengan nilai testing criteria menggunakan persamaan [9].

$$
\begin{array}{ll}
\mathrm{X}=\frac{I}{P} \times 100 \ldots \ldots \ldots \ldots \ldots \ldots \ldots \ldots \ldots \ldots \ldots \\
\mathrm{I} & =\text { Jumlah fungsi yang berhasil diuji } \\
\mathrm{P} & =\text { Jumlah fungsi yang dirancang }
\end{array}
$$

Berdasarkan data yang diperoleh dari hasil expert judgment maka diperoleh hasil perhitungan yaitu 100 . Hal ini dapat diartikan bahwa pada pengujian aplikasi tidak ditemukan adanya fungsi yang dirancang yang tidak berjalan dengan baik sehingga dapat disimpulkan bahwa semua fungsi yang ada pada aplikasi ini dapat berjalan dengan baik.

\section{Pengujian Performa Efficiency}

Berdasarkan hasil pengujian pada Tabel 2 dapat disimpulkan bahwa pengujian performance efficiency berjalan dengan baik yang ditandai dengan proses instalasi dengan menggunakan berbagai perangkat dapat dilakukan tanpa kendala, sedangkan proses berjalannya aplikasi pada perangkat lain juga dapat berjalan dengan baik tanpa adanya kesalahan berupa eror. 
TABEL 2. PENILAIAN PERFORMANCE EFFECIENCY

\begin{tabular}{|c|c|c|c|c|}
\hline No & $\begin{array}{c}\text { Jenis } \\
\text { Perangkat } \\
\text { (Smartphone) }\end{array}$ & $\begin{array}{c}\text { Versi } \\
\text { Android }\end{array}$ & $\begin{array}{c}\text { Proses } \\
\text { Instalasi }\end{array}$ & $\begin{array}{c}\text { Proses } \\
\text { Berjalan } \\
\text { Aplikasi } \\
\end{array}$ \\
\hline 1 & Oppo A71 & $\begin{array}{l}7.1 .1 \\
\text { (Nougat) }\end{array}$ & $\sqrt{ }$ & $\begin{array}{l}\text { Dapat } \\
\text { dijalankan }\end{array}$ \\
\hline 2 & $\begin{array}{l}\text { Oppo A5 } \\
2020\end{array}$ & $10.0(Q)$ & $\sqrt{ }$ & $\begin{array}{l}\text { Dapat } \\
\text { dijalankan }\end{array}$ \\
\hline 3 & Oppo A12 & 9.0 (Pie) & $\sqrt{ }$ & $\begin{array}{l}\text { Dapat } \\
\text { dijalankan }\end{array}$ \\
\hline 4 & Oppo A15 & $10.0 .0(Q)$ & $\sqrt{ }$ & $\begin{array}{l}\text { Dapat } \\
\text { dijalankan }\end{array}$ \\
\hline 5 & $\begin{array}{l}\text { Samsung } \\
\text { Galaxy } \\
\text { A51 }\end{array}$ & $11.0(R)$ & $\sqrt{ }$ & $\begin{array}{l}\text { Dapat } \\
\text { dijalankan }\end{array}$ \\
\hline 6 & Vivo Y12s & $10(Q)$ & $\sqrt{ }$ & $\begin{array}{l}\text { Dapat } \\
\text { dijalankan }\end{array}$ \\
\hline 7 & $\begin{array}{l}\text { Xiaomi } \\
\text { Redmi 4x }\end{array}$ & $\begin{array}{l}7.1 .2 \\
\text { (Nougat) }\end{array}$ & $\sqrt{ }$ & $\begin{array}{l}\text { Dapat } \\
\text { dijalankan }\end{array}$ \\
\hline
\end{tabular}

3. Pengujian Usability

Pada Tabel 3 diperoleh hasil analisis usability yaitu sebanyak 23 orang responden mengatakan aplikasi ini sangat baik dengan nilai persentase $92 \%$ dari jumlah responden dan 2 orang responden menganggap aplikasi ini baik dengan persentase $8 \%$ dari sedangkan untuk kriteria cukup, kurang, dan sangat kurang diperoleh persentase 0 orang atau $0 \%$.

TABEL 3. HASIL PENGUJIAN USABILITY

\begin{tabular}{|c|l|c|c|c|}
\hline No & $\begin{array}{l}\text { Rentan } \\
\text { Skor }\end{array}$ & Frekuensi & Persentase & Kriteria \\
\hline 1 & $\mathrm{X}>63$ & 23 & $92 \%$ & $\begin{array}{c}\text { Sangat } \\
\text { Baik }\end{array}$ \\
\hline 2 & $\begin{array}{l}51<\mathrm{X} \\
\leq 63\end{array}$ & 2 & $8 \%$ & Baik \\
\hline 3 & $\begin{array}{l}39<\mathrm{X} \\
\leq 51\end{array}$ & 0 & $0 \%$ & Cukup \\
\hline 4 & $\begin{array}{l}27<\mathrm{X} \\
\leq 39\end{array}$ & 0 & $0 \%$ & Kurang \\
\hline 5 & $\mathrm{X} \leq 27$ & 0 & $0 \%$ & $\begin{array}{l}\text { Sangat } \\
\text { kurang }\end{array}$ \\
\hline
\end{tabular}

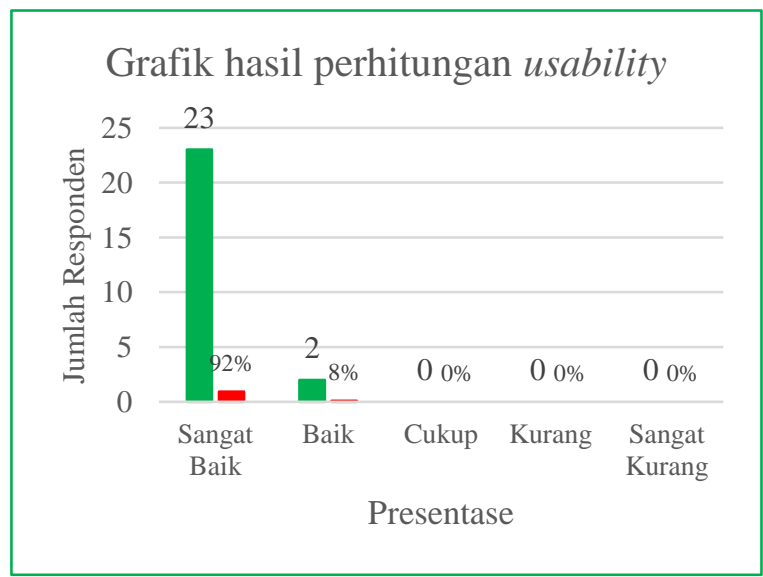

Gambar 5. Grafik Hasil Perhitungan Usability

Berdasarkan hasil analisis dari tanggapan responden terhadap aplikasi pengenalan komponen yang dikembangkan maka diperoleh persentase $92 \%$ dengan hasil kategori baik.

\section{KESIMPULAN}

Hasil penelitian ini yaitu sebuah aplikasi pengenalan komponen elektronika berbasis android. Semua fungsi pada aplikasi ini dapat berjalan berdasarkan hasil pengujian functionality. Aplikasi ini juga dapat digunakan pada perangkat smartphone dengan berbagai tipe dengan sistem operasi android yang berbeda pula berdasarkan hasil analisis performance efficiency. Selain itu aplikasi ini juga dapat dengan mudah dapat digunakan dan cukup membantu dalam pembelajaran berdasarkan hasil pengujian usability.

\section{DAFTAR PUSTAKA}

[1] A. Irmayana and A. Ahyuna, "Aplikasi Pengenalan Simbol Komponen Elektronika Menggunakan Augmented Reality Berbasis Android," Semnasteknomedia Online, vol. 3, no. 1, pp. 4-4-51, 2015.

[2] E. Elfizon, M. Muskhir, and O. Candra, "Pengembangan Media Trainer Elektronika Dalam Pembelajaran Teknik Elektronika Pada Pendidikan Vokasi Teknik Elektro Fakultas Teknik Universitas Negeri Padang," 2017.

[3] K. Kasmirawati, "Aplikasi Pengenlan Komponen Elektronika dengan Augmented Reality Berbasis Android Berdasarkan Kurikulum Mata Kuliah Perguruan Tinggi," Universitas Islam Negeri Alauddin Makassar, 2016.

[4] P. D. Sugiyono, "Metode Penelitian Kuantitatif Kualitatif dan R\&D, Bandung: CV. ALVABETA," 2009.

[5] H. Al Fatta, Analisis dan Perancangan Sistem Informasi untuk keunggulan bersaing perusahaan dan organisasi modern. Penerbit Andi, 2007.

[6] Y. Irawan, "Aplikasi E-Commerce Untuk Pemasaran Kerajinan Tangan Usaha Kecil Menengah (UKM) di Riau Menggunakan Teknik Dropshipping," Jurnal Ilmiah Core IT: Community Research Information Technology, vol. 7, no. 1, 2019.

[7] N. A. Widiastuti, "Aplikasi mobile pada sentra industri seni patung dan ukir di desa mulyoharjo untuk meningkatkan potensi pasar," NJCA (Nusantara Journal of Computers and Its Applications), vol. 3, no. 1, pp. 17-24, 2018.

[8] M. S. Rejeki and A. Tarmuji, "Membangun aplikasi autogenerate script ke Flowchart untuk mendukung business process Reengineering," Universitas Ahmad Dahlan, 2013.

[9] A. Acharya and D. Sinha, "Assessing the quality of m-learning systems using ISO/IEC 25010," International Journal of Advanced Computer Research, vol. 3, no. 3, p. 67, 2013. 